\title{
Cariogenicidade da Merenda Escolar
}

\author{
School Meal Cariogenicity
}

Norma Nabut*

Wagner José Silva Ursi**

NABUT,N. URSI, W.J.S. Cariogenicidade da Merenda Escolar. Semina, Londrina, v. 18, ed. especial, p. $55-62$, fev. 1997.

RESUMO: O objetivo do presente trabalho foi analisar a merenda escolar oferecida em escolas da zona urbana de Londrina, e relacioná-la com os resultados de estudos sobre a influência da dieta na etiopatogenia da cárie dentária, levantando algumas observações a respeito da cariogenicidade da merenda escolar. Para tal, foi esiudado o cardápio de 33 escolas municipais e estaduais, atendidas pela FUNDEPAR - Fundação de Desenvolvimento do Paraná /Programa Municipal de Alimentação Escolar, através da aplicação de um questionário. Constatou-se que a merenda apresenta grandes componentes cariogênicos na maioria das escolas, sem, no entanto, haver técnicas associadas para evitar as suas consequências aos dentes. Sendo assim, este trabalho sugere a implementação de medidas coadjuvantes visando prevenir a doença cárie.

PALAVRAS-CHAVE: Dieta cariogênica; Higiene bucal ; Odontologia preventiva.

ABSTRACT: The objective of this research was to analyze city school meals in Londrina and relate them to the results of studies of the influence of diet on the etiopathogeny of dental caries. Through a questionnaire administered by the Fundação de Desenvolvimento do Paraná/Programa Municipal de Alimentação Escolar (Foundation for the Development of Paraná, Municipal School Meal Program), thirty-three public school menus were examined. It was evidenced that in the majority of these schools the meals contain great amounts of cariogenic components, and no adequate program exists to avoid the consequences. This research suggests the implementation of preventive dentistry.

KEY WORDS: Cariogenic diet; Preventive dentistry.

* Autora: Aluna do $5^{\circ}$ ano de Graduação em Odontologia da Universidade Estadual de Londrina.

** Orientador: Professor Assistente de Materiais Dentários e Dentística da Universidade Estadual de Londrina/Centro de Ciências da Saúde.

rua Pernatmbuco, 5411 - Fone (043) 321-20002 - CEP 860120-070) - Londrina - Paraná. 


\section{INTRODUÇÃO}

A merenda escolar foi implementada no Brasil em 1955, dirigida pelo Ministério da Educação, sendo a operacionalização delegada às secretarias dos Estados e Prefeituras dos Municípios. Sua criação visou reduzir os índices de repetência, evasão e absenteísmo e melhorar o desempenho dos alunos no processo ensino/aprendizagem (COLLARES et al, 1985).

O cardápio da merenda deve suplementar 15\% (por cento) das necessidades diárias dos escolares, ser formulado considerando seu custo, paladar e valor nutritivo. Apresentar alto valor energético, ou seja, entre 280 e $350 \mathrm{Kcal}$ (Quilocalorias) e a sua metabolização rápida, a fim de que atinja imediatamente a corrente sangüínea e possa ser utilizado pelo cérebro. Por essa razão contém carboidratos, como açúcar branco, massas, fubá, arroz e outros alimentos ricos em amido (BARBERATO c TOLEDO, 1991).De acordo com o "Food and Nutrition Board National Academy of Sciences - National Research Council", 1980, cada refeição deve conter uma relação calórico-proteica entre 6 e $8 \%$;um mínimo de $650 \mathrm{U}$ (unidade) de vitamina A, $0,2 \mathrm{mg}$ (miligramas) de vitamina $\mathrm{B} 1,0,2 \mathrm{mg}$ de vitamina B2, 2,0 mg de Ferro (BARBERATO e TOLEDO, 1991).

Ao contrário de muitos municípios brasileiros onde a merenda é municipalizada, Londrina recebe os alimentos da FUNDEPAR (Fundação de Desenvolvimento do Paraná) e a distribuição e gerenciamento são feitos pelo Programa Municipal de Alimentação Escolar. Todas as escolas estaduais de Londrina oferecem merenda escolar, sendo o cardápio elaborado em cada escola.

\section{DIETA E CÁRIE DENTÁRIA}

A importância da dieta na etiologia da cárie é facilmente reconhecida tanto pelos cirurgiões-dentistas como pelos leigos neste campo. Entretanto, o controle da ingestão de alimentos cariogênicos é negligenciada, assim como o aconselhamento dietético por parte dos cirurgiões-dentistas.

A cárie é uma doença crônica que se desenvolve à mercê de 3 fatores fundamentais, quando atuam simultaneamente por um longo período de tempo.
KATZ(1992) resume o processo em forma de diagrama:

\section{Na superficie dos dentes}

dextranos

Organismos

cariogênicos + sacarose

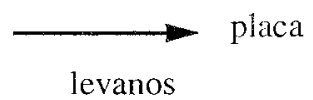

\section{Na placa}

Organismos

cariogênicos + hidratos de carbono $\longrightarrow$ ácidos

\section{Na interface placa-esmalte}

Ácidos + tecidos

dentários susceptíveis

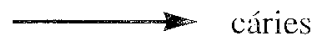

De acordo com o diagrama, a presença de uma flora capaz de formar dextranos ou levanos e placa na boca, usando substratos adequados; a presença na placa de uma flora capaz de fermentar os hidratos de carbono, tanto os provenientes da dieta como os sintetizados intercelularmente pelas bactérias, e, a presença de um substrato cariogênico adequado, como a sacarose e outros hidratos de carbono fermentáveis colaboram na formação da lesão cariosa (KATZ,1982; NEWBRUN, 1988; ALFANO, 1984).

A composição da clieta tem sido considerada como um fator de significativa influência na formação da placa e, posteriormente da cárie dentária, porque a dieta juntamente com a saliva fornece nutrientes para os microorganismos da placa (THYLSTRUP E FEJERSKOV, 1982 E LINDHE, 1982).

O alimento ingerido afeta a cavidade bucal de duas formas: localmente, durante a mastigação até a completa eliminação da cavidade bucal (dieta) e sistemicamentc, após a digestão e absorção, através de suas rotas metabólicas (nutrição) (BARBERATO \& TOLEDO,1991). Os efeitos locais na dieta no metabolismo da placa e, cspecificamente, na produção de ácidos são considerados bem mais relevantes para a cáric do que os efeitos sistêmicos (nutricionais) no 
desenvolvimento do dente e na composição salivar. Contudo, ambos os efeitos, locais e sistêmicos, devem ser considerados se desejarmos compreender completamente a relação entre dieta e cárie dentária (THYLSTRUP e FEJERSKOV,1988).

O excesso de selênio, magnésio, cádmio, platina, paládio e silício durante o período de desenvolvimento dentário, estão associados à maior susceptibilidade à cárie, o mesmo ocorrendo em caso de deficiência de ácido ascórbico, vitamina $\mathrm{A}$, flúor, fosfato e cálcio, que levam à formação de esmalte hipoplásico. Após o irrompimento, a preșença de flúor, cálcio e fosfato na saliva são essenciais à maturação pós-eruptiva do esmalte.

A incidência da cáric através dos séculos pôde ser razoavelmente determinada e apurada porque lesões cariosas podem até ser reconhecidas em dentes que foram enterrados há milhares de anos.

O único material craniano livre de cáries é o de esquimós, datado de antes do contato com a raça branca. Essa população ártica alimentava-se quase que exclusivamente de protcínas e gorduras obtidas através da caça c pesca. Em climas mais amenos, o homem primitivo era um caçador onívero e cołetor de alimentos como ervas, raízes, grãos, frutas e bagas. No período neolítico, cle adquiriu o hábito de criar animais domésticos, cultivar cereais e ingerir alimentos cozidos. Estudos realizados com crânios do homem primitivo revelaran que a cárie ć tão antiga e universalmente presente quanto no homem moderno, mas de baixa prevalência.

Em resumo, a evidência histórica tem demonstrado que havia cáries no homem primitivo. E isso foi altamente exacerbado por uma dieta "civilizada". Os componentes da dieta responsáveis por isso parecem ter sido:

- Antes de nada, o alto teor de carboidratos rapidamente fermentáveis (açúcar e farinha refinada).

- Poucos elcmentos que promovessem mastigação vigorosa, salivação, e limpeza natural da boca nos alimentos modernos.

- Alimentação mais freqüente.

Estudos tền sido realizados sobre a prevalência de cáries em relação a vários níveis de consumo de açúcar e de higiene oral, sendo que em um deles também o uso ou não de flúor foi avaliado. Verificou-se que o efeito cariogênico de um fator era bem maior, quando os outros fatores eram desfavoráveis. Consequentemente, higiene oral e baixa ingestão de açúcar parecem ter uma interação sinérgica ao invés de apenas um efeito aditivo na prevenção da cárie.

Todos os açúcares da dieta sofrem difusão rápida na placa e fermentam, transformando-se em ácidos ou são armazenados sob a forma de polissacarídeos intracelulares pelas bactérias. Entretanto, a sacarose é considerada de maior potencial cariogênico quando comparada a outros carboidratos, pclas seguintes razões:

- É uma molécula pequena e sem carga elétrica, que se difunde facilmente na placa bacteriana (KRASSE, 1985 E KATZ,1982).

- É altamente solúvel e atua como substrato tanto na produção de polissacarídeos extracelulares como na formação de ácido (KRASSE,1985 E THYLSTRUP, 1988).

- Favorece o estabelecimento de Streptococcus mutans sobre os dentes, quando for o microorganismo predominante (KRASSE, 1985). Entretanto, quando não for o predominante, a capacidade de açúcares como glicose, frutose e maltose, para iniciar e manter a progressão da cárie, não é difercnte da sacarose (KATZ, 1982).

- Não contém substâncias que possam inibir a placa bacteriana ou formar uma proteção sobre a superfície do esmalte, pelo contrário, a sua alta ingestão favorece volumosa formação de placa (KRASSE, 1985).

Os Streptococcus mutans não só têm a capacidade de produzir grandes quantidades de ácidos e polissacarídeos extracelulares, mas também intracelulares. $\mathrm{E}$ isto pode servir como um substrato para a produção de ácidos quando cessa o suprimento externo de carboidratos.

O amido é um polissacarídeo da glicose, uma mistura de moléculas de amilose que não formam cadeias ramificadas e de amilopectina, que formam cadeias ramificadas, presentes em várias proporções em diferentes produtos (KRASSE, 1985).

O pH da placa cai muito pouco quando o amido é 
ingerido cru, ou seja, na sua forma insolúvel e está protegido pela celulose. $\mathrm{O}$ seu preparo sob temperatura causa uma degradação parcial formando um amido solúvel que poderá ser decomposto por $\mathrm{X}$-amilases salivares e bacterianas em glicose, maltose, maltotrioses e dextrinas (BIBBY; MUNDORFF, 1975; ADORJAN e STACK, 1976). A associação de sacarose a uma dieta rica em amido, tal como cereais açucarados, bolachas doces, bolos e biscoitos, causa incremento na incidência de cárie (NEWBRUN, THYLSTRUP, FEJERSKOV, 1988).

KRASSE (1985) considera o amido cerca de cinco vezes menos cariogênico que a sacarose, além de que esta favorece o desenvolvimento de cáries em superfícies lisas. Em animais experimentais provou-se que monossacarídeos como glicose e frutose produzem quase duas vezes mais cárie que o amido (MEDEIROS et al, 1995).

Ácidos cítricos e outros ácidos de sucos de frutas e outras bebidas doces causam erosão do esmalte dentário através do contato por longa duração, podendo predispor à cárie, mas certamente o perigo principal de tais produtos é o conteúdo de açúcar.

Embora o mecanismo de atuação não esteja claro, as gorduras reduzem a cariogenicidade dos alimentos. Segundo KATZ, McDONALD e STOOKEY (1982), as gorduras seriam adsorvidas às superfícies dentárias formando uma película protetora que reduzirIA o acúmulo de placa e limitaria o contato de ácido produzido pela placa com o dente. THYLSTRUP e FEJERSKOV (1988), entretanto, sugerem que os lipídeos substituem os carboidratos, tornando-os menos disponíveis, acelerando sua eliminação da cavidade bucal e atuam como dissociadores iônicos, desacoplando o transporte do substrato e a fosforilação oxidativa do transporte eletrolítico da bactéria.

As proteínas têm efeito cariostático, provavelmente por substituírem os carboidratos cariogênicos. Algumas proteínas, especialmente a caseína, ligam-se ao esmalte $\mathrm{e}$ reduzem sua solubilidade in vitro (THYLSTRUP e FEJERSKOV, 1988).

Os fosfatos orgânicos e inorgânicos são importantes na prevenção à cárie. O mecanismo de ação dos fosfatos, teoricamente, é a através da redução do nível de dissolução da hidroxiapatita; efeito tamponante, evitando a queda do pH da placa; remineralização pela deposição de fosfato de cálcio e dissolução de proteínas da superfície do esmalte, alterando a composição e as características da película adquirida (AINAMO e

\section{HOLMBERG, 1974 \& BIBBY,1975).}

Tem-se encontrado que a restrição de carboidratos na dieta, e a substituição destes pelas proteínas e gorduras podem reduzir muito a cárie ou mesmo eliminá-la totalmente (BURNETT et al, 1978).

O potencial produtor de cárie da dieta não é somente pelo seu conteúdo de açúcar. O grau de adesividade do alimento às estruturas bucais é também determinante da habilidade de produção de cárie. A consistência da dieía tem sido considerada importante para uma boa saúde bucal. Assim, alimentos duros e fibrosos estimulam funcionalmente o necessário à manutenção do ligamento periodontal e osso alveolar. Ainda que a ingestão de alimentos duros e fibrosos seja, às vezes, rccomendada como meio de limpeza natural dos dentes, provavelmente ela só é eficaz na redução dos depósitos mais grosseiros da placa, situados em posição mais oclusal ou incisal. Depósitos de placa localizados no terço cervical dos dentes são pouco afetados por esse tipo de dieta. Não é proteção específica (CHAVES, 1986). Outro fator importante para a cariogenicidade é o grau de solubilidade do alimento, o qual se for baixo, restos alimentares permanecen aderidos à superfície dental por maior período de tempo aumentando o potencial cariogênico. Ainda, a frequiência de ingestão de carboidratos influi profundamente no grau cariogênico dos mesmos, assim como o tempo de remoção do alimento da boca (KRASSE, 1986 E NEWBRUN, 1988).

Quando a dieta é cariogênica?

Obviamente, esta pergunta não pode ter resposta curta e precisa. Todos os fatores importantes da doença cárie devem ser levados em consideração e, em relação aos fatores alimentares, considerar o que, como e quando são ingeridos. A resposta pode ser assim formulada:

A dieta é cariogênica quando os outros fatores causadores e os de resistência não estiverem em equilíbrio; os fatores dietéticos relacionados aos produtos são desfavoráveis e o indivíduo come o alimento de maneira imprópria e, primordialmente, quando o momento da eliminação dos restos alimentares da boca for demorado (ADORJAN, 1976 E HOROWITZ, 1971).

\section{MATERIAL E MÉTODO}

Foi estudado o cardápio da merenda escolar oferecida em 33 escolas municipais e estaduais de $1^{\circ}$ e $2^{\circ}$ graus da zona urbana de Londrina, todas atendidas pela FUNDEPAR, através do Programa Municipal de 
Alimentação Escolar.

Os dados foram obtidos através da aplicação de um questionário (em anexo). A partir desses dados foi avaliada a cariogenicidade absoluta e relativa da merenda, identificando os tipos de alimentos, sua consistência e a frequiência com que cada um é oferecido, especialmente os alimentos açucarados. Os dados foram analisados com base em pesquisa bibliográfica.

A fim de calcular o consumo per capita dos alimentos, foram analisados os guias de remessa de alimentos referentes aos meses de novembro e dezembro de 1994, março e abril de 1995 e março e abril de 1996. Verificou-se em quantas escolas as crianças recebem orientação e instrução de higiene, e caso ocorra uma escovação supervisionada, por quem é realizada. Ainda verificou-se a aplicação de flúor.

\section{RESULTADOS}

As 33 escolas onde o questionário foi aplicado atendem 21450 alunos. Na maioria das escolas, o cardápio é elaborado pelas merendeiras e a direção, de acordo com a disponibilidade dos alimentos, sem a orientação de nutricionistas (Tabela 1).

TABELA 1- Orientação de nutricionistas para elaboração do cardápio, em 33 escolas estaduais e municipais de Londrina, 1996:

\begin{tabular}{lcc}
\hline Orientações & No de Escolas $^{0}$ & $\%$ \\
\hline SIM & 02 & 6,06 \\
NÃO & 31 & 93,94 \\
\hline
\end{tabular}

A merenda é servida diariamente, estando os carboidratos (amido e açúcar) presentes em todas as refeições servidas. As refeições doces são servidas pelo menos uma vez na semana, sendo que a maioria das escolas serve estes alimentos 2 vezes por semana (Tabela 2).

TABELA 2- Número de refeições doces por semana, em 33 escolas estaduais e municipais de Londrina, 1996:

\begin{tabular}{ccc}
\hline Vezes/Semana & $\mathrm{N}^{\circ}$ de Escolas & $\%$ \\
\hline 1 & 07 & 21,21 \\
2 & 21 & 63.64 \\
\hline
\end{tabular}

A consistência dos alimentos varia entre líquido, pastoso e sólido.

A média mensal de consumo de açúcar branco per capita é de $75.33 \mathrm{~g}$. O biscoito doce, geralmente servido com leite achocolatado e açucarado, ć o alimento doce mais freqüentemente servido e sua média mensal de consumo per capita é de $65.80 \mathrm{~g}$.

A Tabela 3 mostra os alimentos presentes no cardápio da merenda escolar, a percentagem das escolas onde são servidos, em relação à frequência mensal, assim como o número de escolas que incluem cada item no seu cardápio, em percentual.

Observou-se que a proteína animal e os legumes estão presentes na maioria das refeições salgadas, sendo servidos juntamente com outros alimentos, como
TABELA 3 - Tipos de Alimentos/Freqüência mensal em 33 escolas estaduais e municipais de Londrina, 1996:

\begin{tabular}{l|c|r|r|r|r|r}
\multicolumn{1}{c}{ Freqüência } & 1 & 2 & 3 & 4 & + de 4 & $\%$ das Escolas \\
Alimentos & & & & & & \\
\hline Biscoito Doce & 12,12 & 9,09 & -- & 54,55 & 24,24 & 100,00 \\
Biscoito Salgado & -- & 24,24 & -- & 24,24 & 15,15 & 63,63 \\
Leitc Achocolatado & 15,15 & 15,15 & 6,06 & 30,30 & 30,30 & 90,91 \\
Leite com Café & -- & 6,06 & 6,06 & 9,09 & -- & 21,21 \\
Arroz doce & 27,27 & 36,36 & -- & 36,36 & -- & 100,00 \\
Canjica & 9,09 & 36,36 & 6,06 & 27,27 & -- & 78,78 \\
Sagu & 27,27 & 36,36 & -- & 15,15 & -- & 78,78 \\
Macarronada & -- & 12,12 & 9,09 & 63,64 & 15,15 & 100,00 \\
Polenta & -- & 12,12 & 12,12 & 75,76 & -- & 100,00 \\
Arroz e Feijão & -- & 15,15 & -- & 51,52 & 9,09 & 75,76 \\
Sopa de Legumes & -- & 18,18 & -- & 66,67 & 15,15 & 100,00 \\
Carne & -- & -- & -- & 24,24 & 48,48 & 72,72 \\
\hline
\end{tabular}


macarrão, polenta e sopas. As proteínas animais oferecidas pela FUNDEPAR incluem carne bovina prensada, almôndega e sardinha.

Apenas 6 escolas oferecem frutas esporadicamente, na forma de salada, vitamina ou sucos. Mingau de aveia, chocolate, bolo ou gelatina são servidos uma vez por mês em 8 escolas.

Embora as professoras de todas as escolas orientem seus alunos para a realização da escovação após a merenda, 10 delas não instruem sobre técnicas de higiene bucal, o correspondente a cerca de $30 \%$ das escolas. Em apenas 4 escolas estas instruções são dadas por Técnicos de Higiene Dental, os quais também supervisionam a escovação, junto às professoras, após a merenda. Em 4 outras escolas, a instrução e supervisão são realizadas pelas próprias professoras. Logo, em 75,76\% das escolas não ocorre supervisão da higiene bucal, permitindo que algumas crianças, apesar de orientadas,não realizem a escovação. Ainda foi constado que em todas as escolas são realizados bochechos com flúor, uma vez por semana.

TABELA 4 - Orientação X Instrução de Higiene X Supervisão da higienização em 33 escolas estaduais e municipais de Londrina, 1996:

\begin{tabular}{l|l|l|l}
\hline & $\begin{array}{l}\text { Orientação } \\
\text { Somente }\end{array}$ & $\begin{array}{l}\text { Orientação e } \\
\text { Instrução de } \\
\text { Higiene }\end{array}$ & $\begin{array}{l}\text { Orientação, } \\
\text { Instrução e } \\
\text { Supervisão }\end{array}$ \\
\hline $\begin{array}{l}\mathrm{N}^{\circ} \text { de Escolas } \\
\mathrm{cm} \text { Unidades }\end{array}$ & 10 & 15 & 08 \\
$\begin{array}{l}\mathrm{N}^{\circ} \text { de Escolas } \\
\mathrm{em} \text { Percentual }\end{array}$ & $30,30 \%$ & $45,45 \%$ & $24,24 \%$ \\
\hline
\end{tabular}

\section{DISCUSSÃO}

Conforme os resultados dos estudos sobre cárie dentária, embora os açúcares, especialmente a sacarose e outros carboidratos refinados, sejam essenciais aos seu descnvolvimento, a cárie é uma doença multifatorial. Assim, a relação cntre a ingestão de açúcar, apesar de direta, não ć linear (BARBERATO e TOLEDO, 1991).

Segundo LANKE (1957), além da composição química dos alimentos, propriedades físicas e organolépticas, como tamanho da partícula, solubilidade, adesividade e textura são também importantes para .o estabelecimento e desenvolvimento da lesão cariosa. Ainda, o tempo de remoção dos restos alimentares do meio bucal pode ser prolongado por fatores retentivos $n a$ dentição como cárie, obturações mal feitas, pontes, aparelhos parcialmente removíveis, apinhamentos, pela baixa taxa de secreção ou alta viscosidade salivar ou por baixa atividade muscular.

O presente trabalho permitiu detectar que os cardápios das merendas oferecidas nas escolas de Londrina são cariogênicos tanto em termos absolutos, como relativos. A cariogenicidade absoluta deve-se à presença de carboidratos em todas as merendas e o açúcar en pelo menos uma semanal, o que é agravado pelo fato de o amido ser servido sempre cozido e, muitas vezes, associado à sacarose, como por exemplo, arroz doce, bolacha e canjica. Em termos de cariogenicidade relativa, a merenda é potcncialmente cariogênica devido à consistência e adesividade dos alimentos servidos, assim como pela freqüência de ingestão de carboidratos fermentáveis e, principalmente, pela ausência de higienização bucal supervisionada, após a merenda.

Os alimentos que constituem as refeições doces contêm alta quantidade de sacarose, em sua maioria são de consistência pastosa e grande adesividade.Assim, o arroz doce, o mingau, o sagu e a canjica são desprovidos de ação detergente, pois não exigem mastigação, que é responsável pela remoção mecânica da placa através dos movimentos do alimento, da língua e da estimulação fluxo salivar. $\mathrm{E}$ o biscoito, por exemplo, é um alimento bastante adesivo, o que dificulta sua eliminação da cavidade bucal.

Apesar de tais considerações, o efeito cariogênico de uma única refcição diária, como é a merenda escolar, é questionável. Medidas práticas para acelerar a rennoção de carboidratos consistem, sem dúvida, na escovação imediata após a merenda (RUGG-GUNN et al, 1981).

KOCH e LINDHE (1973) examinaram o efeito da escovação diária supervisionada, em grupos de crianças de 09 a 11 anos, cuja dieta é considerada cariogênica, durante um período de 3 anos. Os resultados demonstraram, claramente, que os bochechos fluoretados quinzenais foram capazes de reduzir o índice de cáries, no entanto, aplicações diárias de dentifrícios fluoretados, em condições supervisionadas, foi o método mais 
eficiente. Notou-se que a combinação de remoção de placa e uso de fluoretos foi mais eficiente do que a de fluoreto isoladamente (McHUGH, 1970).

\section{CONCLUSÃO}

O alto teor de açúcares e carboidratos na merenda, conforme citado anteriormente, é justificado pelas exigências de alto teor calórico e rápida metabolização. Portanto, seria irrealístico propor aqui as alterações ideais que fariam da merenda escolar uma refeição adequada nutricionalmente, sem ser cariogênica. Entretanto, um novo enfoque poderia ser dado, procurando-se medidas práticas e viáveis.

Bochechos com soluções de flúor, através do seu efeito cariostático claramente definido, poderia ser uma alternativa bastante promissora.

O objetivo dos conselhos dietéticos é diminuir os microorganismos produtores de ácidos e aumentar a distribuição proporcional das bactérias não acidúricas e acidogênicas. Isto poderia ser obtido:

- Reduzindo a freqüência das refeições doces;

- Substituindo a ingestão de carboidratos por uma merenda rica em proteínas;

- Na claboração do cardápio, preferir dentre os alimentos doces, aqueles que são mais facilmente eliminados da cavidade aos que apresentam maior adesividade, como os biscoitos doces, o arroz doce $\mathrm{e}$ o mingau;

- Instrução e realização de higiene bucal supervisionada por pessoal capacitado (THDs);

- Bochechos semanais ou quinzenais com flúor 0,05 a 0,2 por cento.

Este trabalho recebeu menção honrosa na Universidade Estadual de Londrina para concorrer ao $6^{\circ}$ Prêmio Kokynos.

\section{REFERÊNCIAS BIBLIOGRÁFICAS}

ADORJAN, S.A.; STACK, M.V. Oral sugar clearance in children. Br. Dent. J.. n.141, p.221-222, 1976.
AINAMO, J.; HOLMBERG, S.M. The oral health of children of dentists. Scand. J. Dent. Res. n.82, p.547-551,1974.

ALFANO, M.C. Nutrição e cárie dentária. In: MENAKER, L. et al. Cáries dentárias. Bases Biológicas. Rio de Janeiro: Guanabara Koogan. 1984. p.302-320.

BARBERATO, M.A.C.; TOLEDO, O.A. Cariogenicidade da merenda escolar. Rev. Gaúcha de Odontol., n.39,2, p.127133, mar/abr.1991.

BIBBY, B.G. The cariogenicity of snack foods and confections. J. Amer. Dent. Assoc. n.90, p.121-132, 1975.

BURNETT, G.W.; SCHERP,H.W.; SCHUSTER, G.S. Microbiologia Oral e Doenças Infecciosas. $4^{2}$ edição. Rio de Janeiro: Guanabara Koogan, 1978. Parte VI, p.214-398.

CHAVES, M.M. Odontologia Social. $3^{\text {a }}$ edição. Artes Médicas. 1986.

COLLARES, C.A. et al. Saúde escolar e merenda: desvios do pedagógico, educação e sociedade. Rev. Gaúcha de Odontol. v.7, n.20, p.10-20, 1985.

HOROWITZ, H.S. et al. The effect on human dental caries of weekly oral rinsing with a sodium fluoride mouth waoh: a final report. Arch. Oral. Biol.. n.16, p609-616, 1971.

KATZ, S.; McDONALD, J.L.; STOOKEY, C.T.K.. Princípios de Nuîrición e Dieta Y Cáries Dental. In: Odontologia Preventiva em Acción. $3^{a}$ edição. Buenos Aircs: Panamericana, 1982, p.247-292.

KOCH, G.; LINDHE, J.. The state of the gengivae and the caries-increment in school - children during and after with drawal of various prophylactic measure. Intern Dent. J., n.23, p.364, 1973.

KRASSE, B.. The cariogenic potencial of foods. A critical review of current methods. Int. Dent. J. n.42, p.35-36, 1985.

KRASSE, B. Risco de Cáries. Guia prático para controle e assessoramento. $2^{\text {a }}$ edição. São Paulo: Quintessence. 1986.

LANKE, L.S. Influence on salivary sugar of certain propertics of foodstuffs and individual oral conditions. Acta Odontol Scand. v.15, n.23, 1957.

LINDHE, J. Tratado de Periodontologia Clínica. Rio de Janeiro: Guanabara koogan, 1982.

MEDEIROS, U.Y.; SPYRIDES, G.M.; FERREIRA, N.A.. Prevenção à cárie através da dieta. Rev. Bras. de Odontol. v.52, n.2, p.42-46, mar/abr, 1995.

PROGRAMA MUNICIPAL DE ALIMENTAÇÃO ESCOLAR. Merenda Escolar. Planejamento e Desenvolvimento. v.57, p.46-51, 1978.

MUNDORFF, S.A. Enamel desmineralization by snack foods. J. Dent. Res. n.54, p.461-470, 1975.

NEWBRUN, E.; Cariologia. $2^{a}$ edição. São Paulo: Santos. 1988

THYLSTRUP, A.; FEJERSKOV, O.. Tratado de Cariologia. Rio de Janeiro: Cultura Médica, 1988. 


\section{A $\quad N \quad E \quad X \quad O$}

\section{CARIOGENICIDADE DA MERENDA ESCOLAR}

01. NOME DA ESCOLA:

02. NÚMERO DE ALUNOS:

03. HÁ ORIENTAÇÃO DE NUTRICIONISTAS PARA A ELABORAÇÃO DO CARDÁPIO?

( ) SIM ( ) NÃO

04. QUAIS OS ALIMENTOS ABAIXO SÃO SERVIDOS? QUAL A FREQÜÊNCIA POR SEMANA?

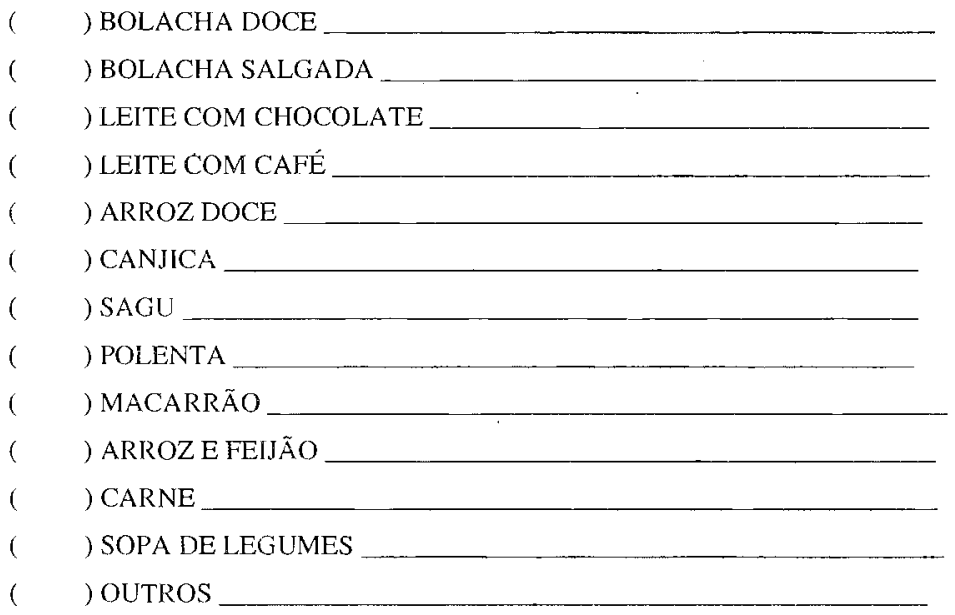

05. QUANTAS REFEIÇÕES DOCES SÃO SERVIDAS POR SEMANA?

( ) UMA ) DUAS ( ) TREAS ( ) MAIS DE 3

06. OS ALUNOS RECEBEM INSTRUÇÃO DE HIGIENE?

\begin{tabular}{clll} 
& $($ ) SIM NÃO & \\
POR QUEM? & $(\quad)$ AUXILIAR DE ODONTOLOGIA \\
$(\quad)$ PROFESSOR & $($ ) OUTROS \\
\hline
\end{tabular}

07. OS ALUNOS SÃO ORIENTADOS A FAZER HIGIENIZAÇÃO APÓS A MERENDA?

\begin{tabular}{cll}
$($ ) SIM & $($ ) NÃO & \\
POR QUEM? & & $(\quad)$ AUXILIAR DE ODONTOLOGIA \\
$(\quad)$ PROFESSORA & $(\quad)$ OUTROS \\
\hline
\end{tabular}

08. É FEITA A ESCOVAÇÃO SUPERVISIONADA?

$$
\text { ( ) SIM ( ) NÃO }
$$

POR QUEM?

( ) PROFESSORA
( MERENDEIRA

09. OS ALUNOS REALIZAM BOCHECHOS COM FLÚOR?

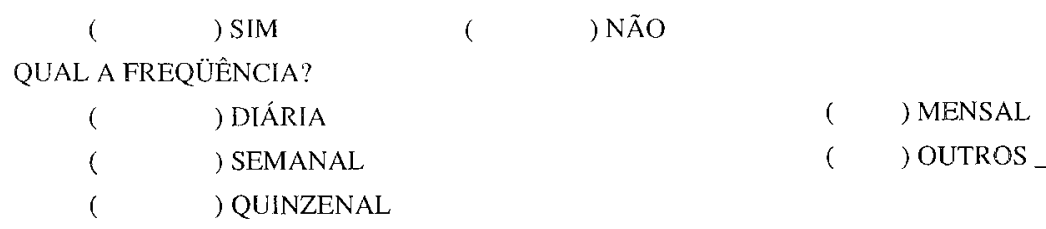

